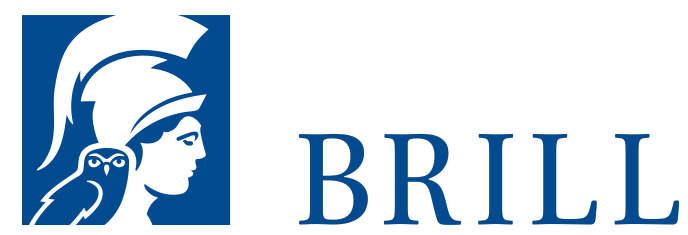

\title{
Die Metapher
}

Kognition, Korpuslinguistik und Kreativität

Author: Ralph Müller

Wann, wie und wozu werden Metaphern verwendet? Auf der Basis von elektronischen Korpora erforscht diese Studie Muster metaphorischer Sprachverwendungen in unterschiedlichen Diskursen und Genres, dies insbesondere in politischen Reden und Gedichten. Die Kognitive Poetik erfasst die Wirkungsweisen dieser Muster; im Zentrum steht die kreative Metapher. Mit dieser Studie können kreative Metaphern (und verwandte Formen der Uneigentlichkeit) in unterschiedlichen Genres erkannt und analysiert werden. Bei mentis erschienen: 'Theorie der Pointe' (2003)

Pages: 260

Seiten

Language:

German

Subjects:

German,

Literature and

Cultural Studies

Publisher: Brill | mentis

Series:

Poetogenesis -

Studien zur

empirischen

Anthropologie

der Literatur,

Volume: 7

E-Book (PDF)

Released online:

14 Feb 2012

ISBN: 978-3-

$89785-872-5$

List price

USD \$54.00

Paperback

Publication date:

14 Feb 2012

ISBN: $978-3^{-}$

89785-457-4

List price

USD $\$ 54.00$ 
For more information see brill.com

Order information: Order online at brill.com +44330 333 0049 | customerservices@brill.com Submission information: brill.com/authors

Titles published by Brill | Fink, Brill | mentis or Brill | Schöningh: +49(o)715413279216| brill@brocom.de 